\title{
Outcomes of Endovascular Therapy for Salvage of Hemodialysis Arteriovenous Fistulae
}

\author{
Nishtha Yadav ${ }^{1}$ Shivanand Gamanagatti ${ }^{2}$ Raju Sharma ${ }^{2}$ Sanjay Kumar Aggarwal ${ }^{3}$ \\ V. K. Bansal ${ }^{4}$ Devasenathipathy Kandasamy ${ }^{2} \quad$ V. Seenu ${ }^{4}$ \\ 1Department of Radiology, Super Speciality Hospital, NSCB Medical \\ Address for correspondence Shivanand Gamanagatti, MBBS, MD, \\ College, Jabalpur, Madhya Pradesh, India \\ ${ }^{2}$ Department of Radiology, All India Institute of Medical Sciences, \\ New Delhi, India \\ ${ }^{3}$ Department of Nephrology, All India Institute of Medical Sciences, \\ New Delhi, India \\ ${ }^{4}$ Department of Surgery, All India Institute of Medical Sciences, \\ New Delhi, India \\ Department of Radiology, All India Institute of Medical Sciences, \\ New Delhi 110023, India (e-mail: shiv223@gmail.com).
}

\section{Abstract \\ Keywords \\ - arteriovenous fistula \\ - hemodialysis access \\ - interventional radiology \\ - balloon dilatation \\ - venoplasty}

Introduction Arteriovenous fistulae (AVF) for hemodialysis (HD) are prone to development of multiple complications, which can lead to nonfunctioning of the fistula. We report outcomes of endovascular management for dysfunctional HD AVF.

Materials and Methods In this prospective study, patients (43 men, 28 women, mean age 47.4 years) with clinical signs and symptoms of dysfunctional HD AVF and referred to interventional radiology for endovascular management were included. The most common clinical presentation included low flows during hemodialysis $(n=20)$, absent flow $(n=37)$, and failure of fistula maturation $(n=14)$. Patients with central venous obstruction who presented with limb swelling were excluded from this study. Patients underwent venography, venoplasty and thrombectomy, as appropriate, to salvage the fistula. The study outcomes were technical success, hemodynamic success, and clinical success of endovascular therapies in salvaging the fistulae.

Results The technical, hemodynamic and clinical success rates of endovascular therapy for low-flow symptoms were $95 \%, 70 \%$ and $95 \%$, respectively. Among patients who presented with absent flow, endovascular therapy had $81 \%$ technical success, $78.3 \%$ hemodynamic success, and $81 \%$ clinical success. Endovascular therapy was associated with $64.2 \%$ technical success, $57.1 \%$ hemodynamic success, and $64.2 \%$ clinical success in patients presenting with failed maturation of the fistula. The overall clinical success rate was $58 / 71(81.7 \%)$ and failure rate was $13 / 71$ (18.3\%). The overall complication rate of endovascular therapy was $8.4 \%$ and the complications included vein rupture in $5(7 \%)$ and balloon rupture in 1 (1.4\%).

Conclusion Endovascular therapy for salvage of nonfunctioning hemodialysis AVF is associated with a high-clinical success rate (81.7\%) and low-complication rate. published online May 21, 2021
DOI https://doi.org/

$10.1055 / \mathrm{s}-0041-1728983$ ISSN 2457-0214
(C) 2021. Indian Society of Vascular and Interventional Radiology. This is an open access article published by Thieme under the terms of the Creative Commons Attribution-NonDerivative-NonCommercial-License, permitting copying and reproduction so long as the original work is given appropriate credit. Contents may not be used for commercial purposes, or adapted, remixed, transformed or built upon. (https://creativecommons.org/licenses/by-nc-nd/4.0/).

Thieme Medical and Scientific Publishers Pvt. Ltd. A-12, 2nd Floor, Sector 2, Noida-201301 UP, India 


\section{Introduction}

Chronic kidney disease (CKD) is a worldwide public health problem. ${ }^{1}$ An Indian population-based study estimated the crude and age-adjusted end-stage renal disease (ESRD) incidence rates at 151 and 232 per million population, respectively. ${ }^{2}$ Hemodialysis is the standard modality of renal replacement therapy for patients with ESRD. In the past, the most important cause of failure of hemodialysis (HD) was the lack of a good vascular access. After the introduction of the Cimino-Brescia fistula in 1966, and with the advent of prosthetic arteriovenous graft (AVG) and central venous catheters (CVCs), physicians have the opportunity to choose among the most appropriate vascular access (VA) for HD patients. The common types of arteriovenous fistula (AVF) are as follows: radiocephalic fistula (RCF), brachiocephalic fistula (BCF), and brachiobasilic fistula (BBF). AVFs remain the first choice for VA because of their higher patency rates, lower rate of complications, and higher overall survival. ${ }^{3}$ However, AVFs are prone to multiple complications, which may lead to nonfunctioning of the fistula. These complications are usually managed by surgical revision or endovascular therapy. While there is extensive data from the developed countries on the effectiveness of endovascular therapy for salvage of dysfunctional AVFs, a similar data from India is lacking. Thus, the purpose of this study is to report outcomes of endovascular interventions in the management of dysfunctional AVFs from our center in India.

\section{Materials and Methods}

This was a prospective study performed over 19 months between August 2013 to March 2015. Ethical approval was obtained from our institute's ethics board. Informed consent was obtained from all patients. The following were inclusion criteria: All patients with clinical signs and symptoms of AVF dysfunction and referred to the Department of Radiodiagnosis for interventional management during the period of study, with age $>18$ years and with the ability to give informed consent. Exclusion criteria included patients with age less than 18 years, inability to provide informed consent, allergy to contrast media, cellulitis, and patients with central venous stenosis (evaluated separately). The patients were assessed by Doppler ultrasound for the cause of fistula dysfunction, and suitable patients were treated with appropriate interventional procedures. Patients with central venous obstruction who presented with limb swelling were excluded from this study.

\section{Patients and Clinical Presentation}

As many as 101 patients were evaluated clinically and all of them underwent Duplex ultrasound evaluation. Thirty patients presented with nonfunctioning fistula with absent flow for more than 30 days and had collapsed and fibrosed vein throughout and were not amenable for intervention. The remaining 71 patients were evaluated for site of stenosis/thrombosis or other causes of decreased flow. Among these patients, there were 53 cases of RCF (74.6\%), 16 cases of BCF (22.6\%), and 2 cases of BBF (2.8\%).

\section{Demographic Details}

Patients had a mean age of 47.4 years (range $14-80$ years). Most of the patients were in their sixth decade, with male to female ratio being 1.5:1.

\section{Clinical Background}

Patients in the study had CKD with surgical AVF in upper limb, and they were either undergoing dialysis through AVF or were to be started on dialysis through AVF. They were referred with nonfunctioning AVF/graft, with the following presenting complaints: decreased flow during dialysis $(n=$ $20,22.2 \%$ ), absent flow/thrill during/after dialysis $(n=37$, $41.1 \%)$, and failure to mature $(n=14,15.5 \%)$. The mean duration of presentation for dysfunctional fistulas who presented with absent flow or decreased flow during HD was 3.2 days (ranging from 1-7 days). According to institutional surveillance protocol, patients were monitored at 1, 4, and 12 weeks for fistula maturation using Duplex ultrasound. Thirteen patients were taken up for venoplasty when they presented with failure of AVF to mature at 4 weeks (three patients who had stenosis+thrombosis) to 12 weeks (ten patients who had decreased flow on Doppler evaluation) after fistula creation.

\section{Duplex Doppler Evaluation}

These patients were evaluated using Duplex Doppler and high-frequency linear probe. Artery, fistula site, and veins were evaluated to look for patency of vessels, presence of thrombosis/stenosis, and presence of branching veins. Flow volume was calculated in the patent fistulae which presented with decreased flow. Flow volumes was calculated as "area $\times$ mean velocity $\times 60$." The vessel diameter was calculated on B-mode ultrasound. The mean flow velocity was calculated from the time/velocity curve (using the time-averaged velocity option).

Stenosis was noted in $n=26$ (36.6\%) cases, thrombosis in $n=29$ (40.9\%) cases, stenosis+thrombosis in $n=15$ (21.1\%) cases, and branching of veins in midforearm was noted in $n$ $=1(1.4 \%)$ case $(-$ Table $\mathbf{1})$. One patient had calcification of radial artery in addition to stenosis of outflow vein. The various sites of stenosis are shown in - Table 2 . The most common site of stenosis was juxta-anastomotic (60.9\%). Mean length of stenosis was $23 \mathrm{~mm}$.

Patients who had distended vein amenable for puncture were taken up for venoplasty. In patients with collapsed vein, tourniquet was applied and Doppler evaluation was done along the course of vein to look for distensible segment, which can be used for puncture. Patients who had long segment fibrosed vein with no distensible segment were considered nonamenable for intervention.

\section{Interventional Therapies}

Seventy-one patients were taken up for venography procedure. Transvenous access was used in all patients. Under strict aseptic precautions, vein was punctured using micropuncture introducer set (Cook Medical, Bloomington, IN) /18G intravenous cannula in compressible and distensible part of proximal forearm (RCF) or in proximal arm (BCF/BBF). Tourniquet was tied proximally to distend the target vein. 
Table 1 Lesions noted on doppler evaluation in dysfunctional fistula group $(n=71)$

\begin{tabular}{|l|l|l|}
\hline Clinical presentation & Lesion on Doppler & Number \\
\hline \multirow{3}{*}{ Decreased flow $(n=20)$} & Stenosis & 16 \\
\cline { 2 - 3 } & Thrombosis & 2 \\
\cline { 2 - 3 } & Stenosis + thrombosis & 2 \\
\hline Absent flow $(n=37)$ & Thrombosis & 27 \\
\cline { 2 - 3 } & Stenosis + thrombosis & 10 \\
\hline Failure to mature $(n=14)$ & Stenosis & 10 \\
\cline { 2 - 3 } & Stenosis + thrombosis $^{\mathrm{a}}$ & 3 \\
\cline { 2 - 3 } & $\begin{array}{l}\text { Branching of vein in } \\
\text { mid forearm }\end{array}$ & 1 \\
\hline Total $(n=71)$ & & 71 \\
\hline
\end{tabular}

ane patient had radial artery calcification in addition to outflow vein stenosis.

Table 2 Site of stenosis

\begin{tabular}{|l|l|l|}
\hline $\begin{array}{l}\text { Type of } \\
\text { arteriovenous } \\
\text { fistula }\end{array}$ & Site of stenosis & $\begin{array}{l}\text { Number of } \\
\text { patients }\end{array}$ \\
\hline Radiocephalic & Juxta-anastomotic & 20 \\
\cline { 2 - 3 } & Body of fistula & 10 \\
\hline Brachiocephalic & Juxta-anastomotic & 5 \\
\cline { 2 - 3 } & Body of fistula & 1 \\
\cline { 2 - 3 } & Cephalic arch & 3 \\
\cline { 2 - 3 } & $\begin{array}{l}\text { Multiple stenosis } \\
\text { at anastomotic site } \\
\text { and body of fistula }\end{array}$ & 1 \\
\hline Brachiobasilic & Swing site stenosis \\
fistula & 1 \\
\hline
\end{tabular}

Following venous access, 6Fr arterial sheath was placed. Images of the complete venous outflow were acquired by repeated manual injection of 5 to $10 \mathrm{~mL}$ of the nonionic contrast material. Following venography, 0.035" angled hydrophilic guidewire (Glidewire; Terumo, Somerset, NJ) was negotiated through stenotic/thrombotic segment under fluoroscopy and USG guidance. AVF site was traversed by guidewire, with distal end of wire positioned in artery. Following this, venoplasty was done using standard balloon catheter (Advance 35 LP, Cook Medical, Bloomington, IN) of appropriate size (4-8 $\mathrm{mm}$ diameter, $4 \mathrm{~cm}$ length) over 0.035 " angled hydrophilic guidewire (Glidewire; Terumo, Somerset, NJ), and balloon dilatation of the stenotic segment and/or maceration of thrombus was done. Balloon inflation was done for 1 to 3 minutes. Thrombectomy was done by aspiration of thrombus through the $6 \mathrm{~F}$ sheath. Thrombolysis was not performed. Postprocedure venography was repeated.

Following the interventional procedure, patients were evaluated to look for evidence of technical success. Patients were then followed up on the 2nd and 10th day with Doppler ultrasound to assess hemodynamic success. Patients were also followed-up clinically to assess clinical success for a period of 30 days.

\section{Definitions}

Technical success was defined by presence of thrill, venogram study showing restoration of blood flow, and absence of stenosis/thrombosis immediately after the endovascular procedure, without any procedural complication leading to failure. Technical failure was defined as absence of thrill with persistence of stenosis/thrombosis immediately following the procedure.

Hemodynamic success was defined as flow volume $>500 \mathrm{~mL} / \mathrm{min}$, vein diameter $>4 \mathrm{~mm}$ and skin to vein distance $<6 \mathrm{~mm}$ (measured by Doppler studies on 2nd and 10th day following the endovascular procedure).

Clinical success was defined as the ability to undergo successful dialysis through the fistula with adequate flow for minimum of 30 days following the endovascular procedure.

Clinical failure was defined as the inability to complete a successful hemodialysis through the fistula following the endovascular procedure.

\section{Results}

\section{Outcome in Patients with Decreased Flow in the AVF}

Twenty patients who presented with decreased flow through fistula during dialysis underwent venoplasty procedure after Doppler evaluation. Two patients had thrombosed fistula. There were 18 patients who had stenotic lesions. The most common site of stenosis was juxta-anastomotic $(n=$ $12,66.6 \%)$; other sites being body of fistula ( $n=5,27.7 \%)$ and cephalic arch $(n=1,5.5 \%)$. There were no patients with arterial stenosis. Balloon catheter (Advance 35 LP, Cook Medical, Bloomington, IN) of sizes 4 to $8 \mathrm{~mm}$ were used. Stents were not used in any patient.

The clinical success in this group was achieved in 19/20 cases (95\% clinical success rate) Procedural complication in the form of venous rupture was noted in 2 patients. Technical and hemodynamic success were noted in $95 \%$ and $70 \%$ cases, respectively ( - Table 3 ).

\section{Outcome in Patients with Absent Flow/Thrill in the AVF During/After Dialysis}

Thirty-seven patients who presented with absent flow/thrill in the fistula during/after dialysis underwent venoplasty procedure after Doppler evaluation. Twenty-seven patients had thrombosis of fistula. There were 10 patients who had stenotic lesions. The sites of stenosis were juxta-anastomotic

Table 3 Outcome of venoplasty in dysfunctional fistula group in patients presenting with decreased flow $(n=20)$

\begin{tabular}{|l|l|l|}
\hline & $N$ & $\begin{array}{l}\text { Percentage }(N / 20) \\
\times 100\end{array}$ \\
\hline Technical success & 19 & 95 \\
\hline $\begin{array}{l}\text { Hemodynamic } \\
\text { success }\end{array}$ & 14 & 70 \\
\hline Clinical success & 19 & 95 \\
\hline Technical failure & 1 & 5 \\
\hline Clinical failure & 1 & 5 \\
\hline
\end{tabular}


( $n=3,30 \%)$, body of fistula $(n=3,30 \%$ ), cephalic arch ( $n=2,20 \%)$, swing site in $\operatorname{BBF}(n=1,10 \%)$, and multiple sites of stenosis involving juxta-anastomotic site and body of fistula ( $n=1,10 \%)$. There were no patients with arterial stenosis. Balloon catheter (Advance 35 LP, Cook Medical, Bloomington, IN) of sizes 4 to $8 \mathrm{~mm}$ were used. Stents were not used in any patient.

Clinical success was achieved in 30/37 cases (81\% clinical success rate). Technical and hemodynamic success were noted in $81 \%$ and $78.3 \%$ cases, respectively ( - Table 4 ). Procedural complication (venous rupture) was noted in 3 patients.

\section{Outcome in Patients with Failure of AVF to Mature}

Fourteen patients who presented with failure to mature underwent venography+/-venoplasty procedure after Doppler evaluation. One patient had multiple branching veins in forearm. Stenotic lesions were noted in 13 patients. The most common site of stenosis was juxta-anastomotic ( $n=10,76.9 \%$ ), with the other site being body of fistula ( $n=3,23.1 \%$ ). Additionally, inflow artery calcification was noted in 1 patient and attenuated inflow artery in another patient. Balloon catheter (Advance 35 LP, Cook Medical, Bloomington, IN) of sizes 4 to $8 \mathrm{~mm}$ were used. Stents were not used in any patient.

Clinical success was achieved in 9/14 cases (64.2\% clinical success rate). Technical and hemodynamic success were noted in $64.2 \%$ and $57.1 \%$ cases, respectively (-Table 5).

\section{Overall Outcomes}

Overall clinical success rate among the 71 patients who underwent endovascular therapy was 58/71 (81.7\%) and the failure rate was $13 / 71$ (18.3\%). None of the patients required repeat intervention during 1-month follow-up. Examples

Table 4 Outcome of venoplasty in dysfunctional fistula group in patients presenting with absent flow $(n=37)$

\begin{tabular}{|l|l|l|}
\hline & $N$ & $\begin{array}{l}\text { Percentage } \\
(N / 37) \times 100\end{array}$ \\
\hline Technical success & 30 & 81 \\
\hline $\begin{array}{l}\text { Hemodynamic } \\
\text { success }\end{array}$ & 29 & 78.3 \\
\hline Clinical success & 30 & 81 \\
\hline Technical failure & 7 & 18.9 \\
\hline Clinical failure & 7 & 18.9 \\
\hline
\end{tabular}

Table 5 Outcome of venoplasty in dysfunctional fistula group in patients presenting with failure to mature $(n=14)$

\begin{tabular}{|l|l|l|}
\hline & N & $\begin{array}{l}\text { Percentage } \\
(N / 14) \times 100\end{array}$ \\
\hline Technical success & 9 & 64.2 \\
\hline $\begin{array}{l}\text { Hemodynamic } \\
\text { success }\end{array}$ & 8 & 57.1 \\
\hline Clinical success & 9 & 64.2 \\
\hline Technical failure & 5 & 35.7 \\
\hline Clinical failure & 5 & 35.7 \\
\hline
\end{tabular}

of cases with successful venoplasty in case with decreased flow and absent flow are shown in - Fig. 1 and - Fig. 2, respectively.

\section{Causes of Failure}

Failure rate in endovascular management of dysfunctional fistula was $18.3 \%$. Causes of failure include failure to cross the area of stenosis in 1 , long segment thrombosis in 5 , tight stenosis leading to rupture of the vein during dilatation in 2, branching of veins leading to flow diversion in 1, inflow artery calcification in 1 , attenuated inflow artery in 1 , and unknown in 2. For the patient who had multiple branching veins in forearm, option of endovascular coiling was given to the patient; however, the patient could not afford the cost of the procedure.

\section{Complications and Their Management}

Complications noted in our study were balloon rupture in $1(1.4 \%)$ and vein rupture in $5(7 \%)$ patients.

Balloon rupture was noted when an attempt was made to dilate an area of tight stenosis in the cephalic arch entering the subclavian vein. Balloon catheter was recovered immediately. Dilatation was done using a smaller balloon catheter and the procedure was technically successful.

Vein rupture was noted in 5 patients. It occurred when an attempt was made to dilate a region of tight stenosis (3 patients), and during dilatation of a chronically fibrosed long-standing venous occlusion (2 patients).

Vein rupture was managed with manual compression for 15 to 20 minutes at the rupture site in 4 patients. However, balloon tamponade with $4 \mathrm{~mm}$ balloon was required for 15 to 20 minutes in 1 patient, as vein rupture was close to AVF site (which was patent, thus leading to increased extravasation). None of the patients required placement of stent graft to stop the extravasation. Following treatment of vein rupture, successful venoplasty during the same setting was performed in 3 patients, while 2 patients had clinical failure. Complications are shown in -Fig. 3.

\section{Discussion}

We assessed the effectiveness and safety of endovascular procedure for salvage of nonfunctioning AVFs, presenting as decreased flow, absent flow, or failure to mature. Doppler evaluation revealed the underlying lesion as thrombosis, stenosis with/without thrombosis, and branching of veins. These lesions were treated with balloon venoplasty with balloon dilatation.

Clinical success was achieved in $95 \%$ of patients who presented with decreased flow in AVF, $81 \%$ of patients who presented with absent flow, and $64 \%$ of patients with failure of AVF to mature. Overall clinical success was noted in $81.7 \%$ cases (58/71).

The traditional approach for endovascular treatment of dysfunctional dialysis access has been the transvenous antegrade or retrograde puncture of the fistula, which was also used in our study. However, transradial approach can also be used and is advantageous in cases of a juxta-anastomotic 

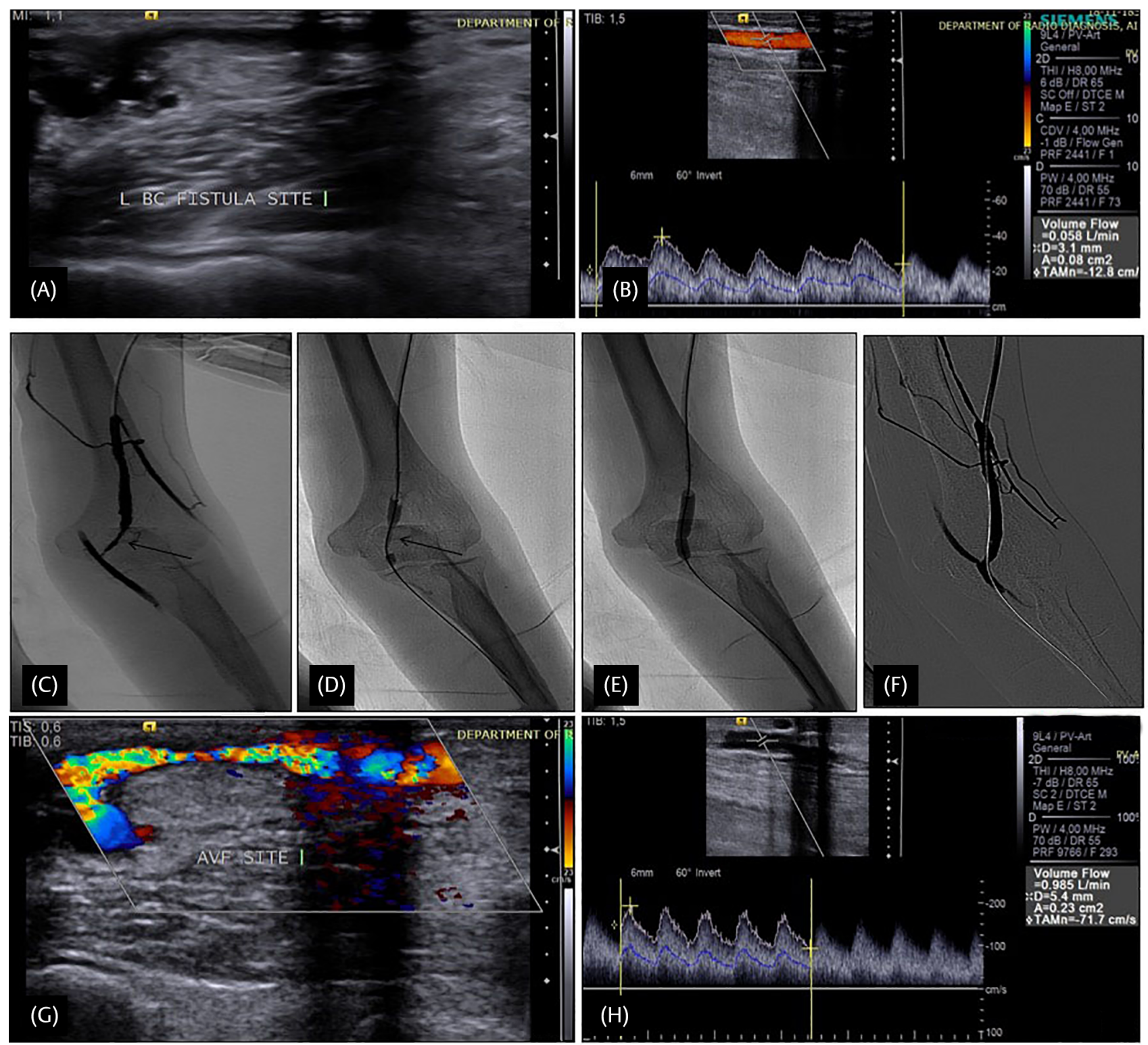

Fig. 1 Example of venoplasty in a patient with decreased flow through fistula during dialysis. Doppler evaluation of a 47-year-old patient with decreased flow in left brachiocephalic fistula (BCF) revealed (A) patent left BCF site, with (B) decreased flow in outflow vein (58 $\mathrm{mL} / \mathrm{min}$ ) insufficient for dialysis. Venogram study (C) revealed stenosis of outflow vein just distal to anastomosis site (arrow). (D) Balloon dilatation was done using $8 \mathrm{~mm} \times 4 \mathrm{~cm}$ balloon catheter, which showed presence of waist (arrow) at site of stenosis (E) Further inflation of balloon led to disappearance of waist and dilatation of stenosis. Postdilatation run $(\mathbf{F})$ shows increased caliber of vein with increased flow with no periprocedural complication. Postvenoplasty Doppler revealed (G) patent AVF site. (H) Increased flow volume of $985 \mathrm{~mL} / \mathrm{min}$ and vein diameter $5.4 \mathrm{~mm}$ were noted on tenth day following intervention.

stenosis, multiple proximal venous outflow stenosis, or lesions in both limbs of the AVF. ${ }^{4}$ After obtaining access, venography reveals the sites of stenosis/occlusion. The stenotic lesion is crossed by 0.035 " guidewire, noncompliant balloon is tracked over the wire, and angioplasty is performed. Usually 1 to 3 minutes inflation time for standard balloon is enough for most patients. Ultrahigh-pressure/cutting/drug-eluting balloon may be required for resistant cases. Mechanical thrombectomy with thromboaspiration or pharmacological thrombolysis may be required in cases with extensive thrombus burden.

Bittl et al noted that catheter-based interventions are successful in restoring flow in more than $80 \%$ of HD accesses that undergo thrombosis and have replaced surgical revision as the treatment of choice for failing or thrombosed accesses. ${ }^{5}$ Nikam et al performed percutaneous intervention of thrombosed AVF in the form of various procedures including balloon maceration, mechanical thrombolysis (Angiojet/Trerotola), angioplasty, in situ pharmacological thrombolysis, and stenting. ${ }^{6}$ The initial radiological success was achieved in $86.7 \%$ cases. Clinical success, defined by a successful first dialysis, was $81.9 \%$. In a study by Cohen et al, angiography was done in 43 patients with dysfunctional fistula revealing juxta-anastomotic stenosis/thrombosis. $^{7}$ Following percutaneous intervention, immediate postprocedural angiography demonstrated an angiographic 


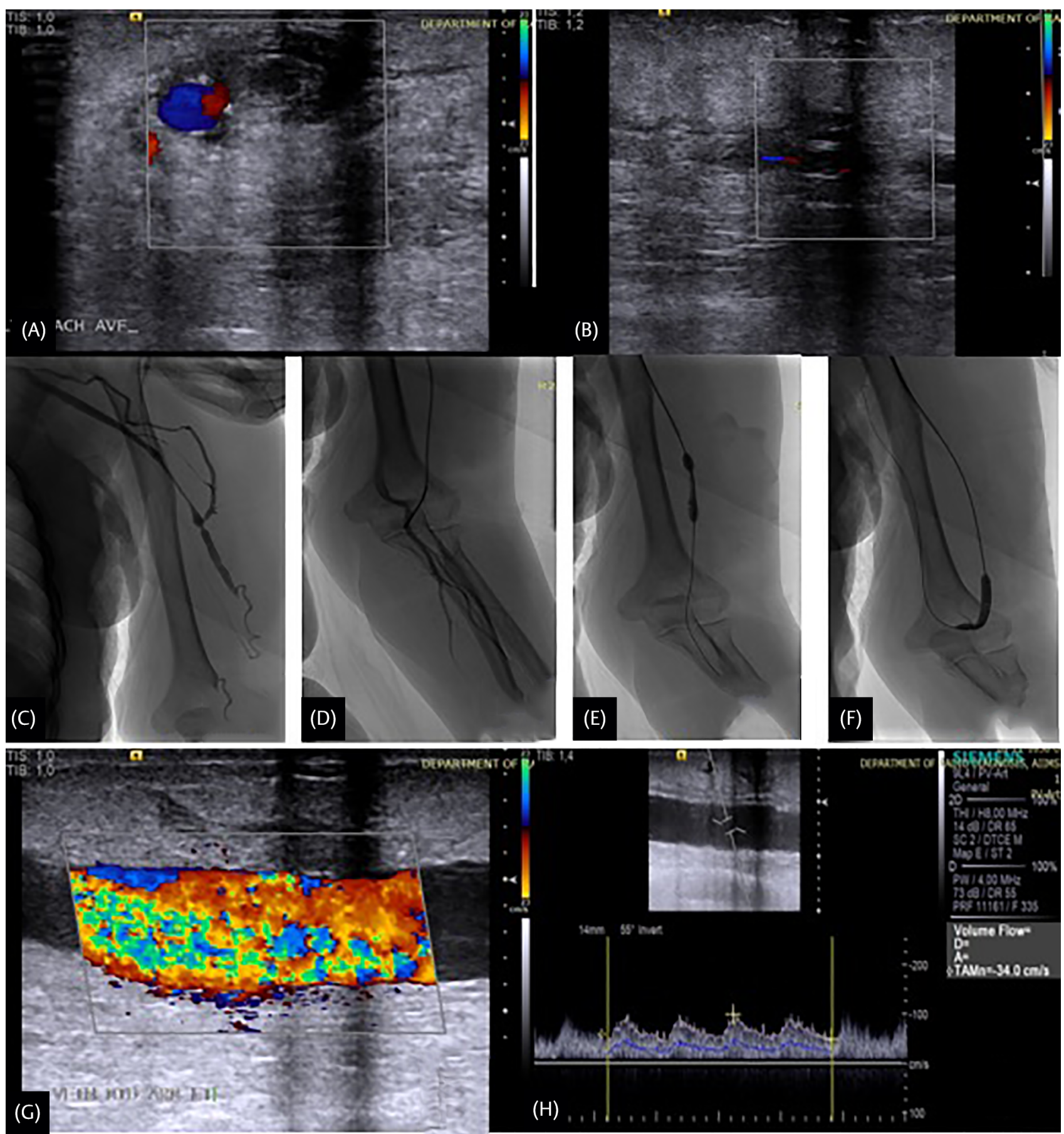

Fig. 2 Example of venoplasty in a patient with absent flow through fistula during dialysis. Doppler evaluation in a 56-year-old patient with absent flow in left brachiocephalic fistula (BCF) revealed (A) thrombosed BCF site with (B) thrombosed vein. Venogram study (C) revealed nonopacification of outflow vein in lower and midarm with segmental stenosis in upper arm. (D) Anastomotic site was traversed, and distal end of guidewire and multipurpose angiographic catheter noted in brachial artery. Balloon dilatation was done using $8 \mathrm{~mm} \times 4 \mathrm{~cm}$ balloon catheter, which showed presence of waist in lower and mid arm (E, F); further inflation showed disappearance of waist of balloon. Postvenoplasty Doppler (G) revealed patent brachiocephalic arteriovenous fistulae (AVF) site with increased flow volume of $1298 \mathrm{~mL} / \mathrm{min}$ and vein diameter $9.0 \mathrm{~mm}$ on tenth day following intervention $(\mathbf{H})$.

success rate of $98 \%$. Clinical success, with at least one session of normal dialysis, occurred in $95 \%$ of interventions (which was similar to our study). Recently, drug-eluting balloons are being tried for stenosis in native HD fistulas, and in a study by Yildiz et al, there was a nonsignificant tendency for lower rate and a delay for recurrent dysfunction in patients treated with paclitaxel drug-eluting balloon. ${ }^{8}$
We achieved $64 \%$ success rate in salvage of fistulas that failed to mature. Miller et al were able to salvage $97 \%(118 / 122)$ of nonmatured AVFs with a more aggressive approach to dilating diffusely strictured veins, forced balloon-assisted maturation of deep veins up to $16 \mathrm{~mm}$ in diameter, and elimination of nearly all distal and midfistula collateral vein. ${ }^{9}$ Turmel-Rodrigues et al achieved $97 \%$ clinical success 

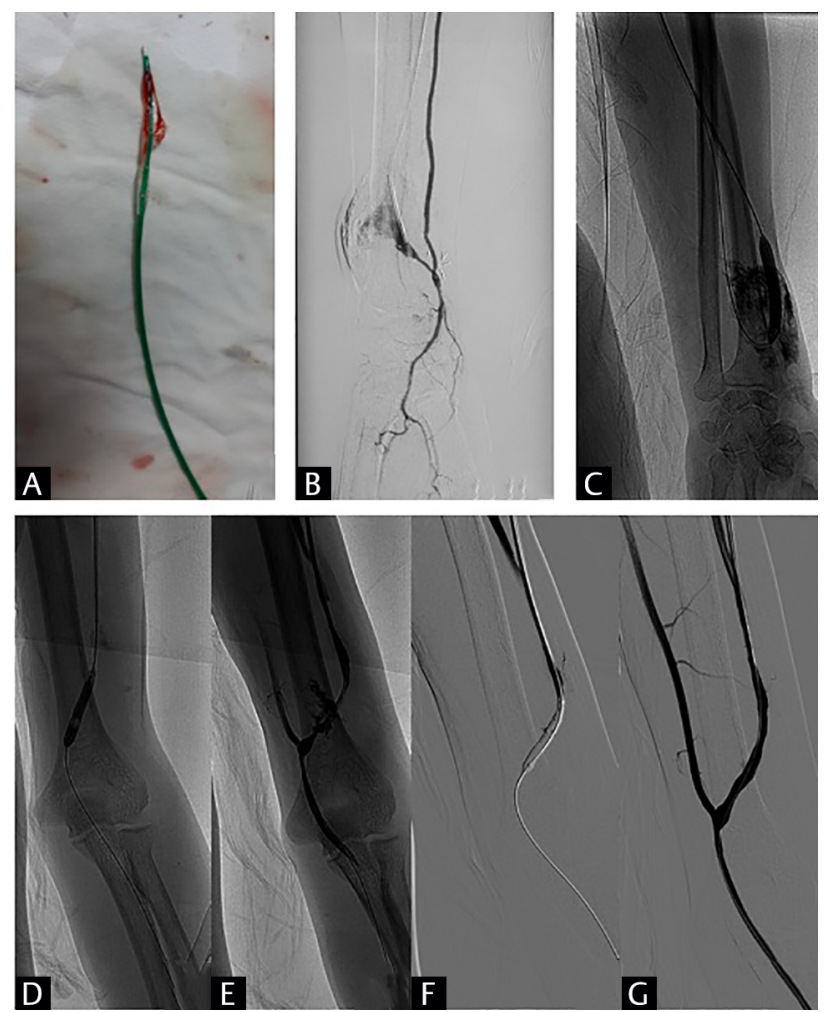

Fig. 3 Complications during venoplasty (A) Balloon rupture during dilatation of cephalic vein entering subclavian vein at a region of tight stenosis. (B) Cephalic vein rupture with contrast extravasation during dilatation of a region of tight stenosis. It was managed by manual compression (C) Cephalic vein rupture with persistent contrast staining of subcutaneous tissue when attempt was made to dilate a chronically fibrosed venous segment. It was managed by manual compression. (D) Balloon dilatation of cephalic vein at left brachiocephalic arteriovenous fistulae (AVF) anastomotic site. (E) Active contrast extravasation was from venous side. (F) Balloon was kept inflated at that segment for 20 to 25 minutes. (G) Contrast study done subsequently shows no contrast extravasation with patent cephalic vein with increased flow.

in salvage of immature forearm fistulas by interventional procedures. ${ }^{10}$ Beathard et al published that access was salvaged in 52 out of 63 patients (82.5\%). ${ }^{11}$ In another study by Miller et al, 111 (79\%) fistulas matured through sequential angioplasty procedures and became usable for HD (clinical success)..$^{2}$ In a study by Nassar et al of endovascular management of "failure to mature" fistulas, the technique was successful in 107 (89.9\%) cases, and the AVF was salvaged in 99 (83.2\%) cases. ${ }^{13}$ Park et al obtained a clinical success in $94 \%$ cases using endovascular techniques to achieve maturity of fistula. ${ }^{14}$ Lee et al obtained technical and clinical success rate of $88.9 \%$ and $85.2 \%$, respectively in endovascular management of AV fistula. ${ }^{15}$ Thus, the success in patients with fistulas which fail to mature was lower in our study (64\%) as compared with others. However, the number of patients in this group was only 14 , and success was noted in 9 patients, while failure was noted in 5 patients. The causes of failure in these cases were inflow artery calcification $(n=1)$, attenuated inflow artery $(n=1)$, accessory veins $(n=1)$, and unknown $(n=2)$. Thus, failure in this group was due to inflow lesions and accessory veins, both of which were not separately managed in our study. Coil embolization of deep accessory veins has been described in studies; however, it was not done in any of our cases. ${ }^{9,11}$

Complications noted after intervention in our study were balloon rupture in one case (1.4\%) and vein rupture in five cases (7\%). This is comparable to other studies.

We encountered a case of balloon rupture, which was removed intact, and no vessel damage was noted. Unfortunately, a large number of venous stenoses are very resistant to conventional angioplasty and are not resolved with routine pressures (12 to 20 atmospheres). Moreover, conventional percutaneous transluminal angioplasty (PTA) balloons may rupture during dilatation at higher pressures, thus potentially damaging the venous wall. ${ }^{16,17}$

In our study, there were 5 patients who developed venous rupture during angioplasty; four of them were managed by manual compression, and one required prolonged balloon tamponade at the rupture site. No patient required stenting to manage venous rupture. Successful control of bleeding was observed in all patients, of whom 3 underwent successful venoplasty, while 2 patients encountered technical and clinical failure. Vessel rupture and perforation have been identified as potential complications of percutaneous treatment and may occur in $<1 \%$ of cases. ${ }^{18,19}$ One study suggested that using a balloon catheter more than $2 \mathrm{~mm}$ larger than the diameter of the HD access or using peripheral cutting balloons increased the risk of rupture. Miller et al noted five instances (out of 140 interventions) of angioplasty-induced vein rupture. ${ }^{12}$ Turmel-Rodrigues et al noted that nine acute venous ruptures occurred during dilatation (13\%), seven of which were managed by prolonged balloon dilatation, while two required stenting. ${ }^{10}$

Our study has the following limitations: Patients were assessed for success of procedure by Duplex ultrasound evaluation on the second and tenth day following procedure and followed-up clinically to ensure successful dialysis for a period of 30 days, which defined the clinical success in our study. Further follow-up to assess long-term patency was not performed. Pharmacological thrombolysis for thrombosis and coil embolization for accessory veins was not performed in our study.

\section{Conclusion}

Endovascular management for salvage of nonfunctioning fistulas is safe and effective method with high-clinical success rate $(81.7 \%)$. Optimal patient selection can further increase success and decrease the rate of complications during intervention.

\section{Conflict of Interest}

None declared. 


\section{References}

1 Schieppati A, Remuzzi G. Chronic renal diseases as a public health problem: epidemiology, social, and economic implications. Kidney Int Suppl 2005;68(98):S7-S10

2 Jha V. Current status of end-stage renal disease care in India and Pakistan. Kidney Int Suppl 2013;3(2):157-160

3 Santoro D, Benedetto F, Mondello P, et al. Vascular access for hemodialysis: current perspectives. Int J Nephrol Renov Dis 2014;7:281-294

4 Le L, Brooks A, Donovan M. Smith TA, Sternbergh WC III, Bazan HA. Transradial approach for percutaneous intervention of malfunctioning arteriovenous accesses. J Vasc Surg 2015;61(3):747-753

5 Bittl JA. Catheter interventions for hemodialysis fistulas and grafts. JACC Cardiovasc Interv 2010;3(1):1-11

6 Nikam M, D, Ritchie J, Jayanti A, Bernstein O, A, Ebah L, Brenchley P, Hutchison A, Chalmers N, Mitra S: Acute Arteriovenous Access Failure: Long-term outcomes of endovascular salvage and assessment of co-variates affecting patency. Nephron 2015;129:241-246

7 Cohen A, Korzets A, Neyman H, et al. Endovascular interventions of juxtaanastomotic stenoses and thromboses of hemodialysis arteriovenous fistulas. J Vasc Interv Radiol 2009;20(1):66-70

8 Yildiz I. The efficacy of paclitaxel drug-eluting balloon angioplasty versus standard balloon angioplasty in stenosis of native hemodialysis arteriovenous fistulas: an analysis of clinical success, primary patency and risk factors for recurrent dysfunction. Cardiovasc Intervent Radiol 2019;42(5):685-692

9 Miller G, Friedman A. Balloon-assisted maturation of arteriovenous fistulas Endovasc Today 2010;46-54
10 Turmel-Rodrigues L, Mouton A, Birmelé B, et al. Salvage of immature forearm fistulas for haemodialysis by interventional radiology. Nephrol Dial Transplant 2001;16(12):2365-2371

11 Beathard GA, Settle SM, Shields MW. Salvage of the nonfunctioning arteriovenous fistula. Am J Kidney Dis 1999;33(5):910-916

12 Miller GA, Hwang W, Preddie D, Khariton A, Savransky Y. Percutaneous salvage of thrombosed immature arteriovenous fistulas. Semin Dial 2011;24(1):107-114

13 Nassar GM, Nguyen B, Rhee E, Achkar K. Endovascular treatment of the "failing to mature" arteriovenous fistula. Clin J Am Soc Nephrol 2006;1(2):275-280

14 Park HS, Lee YH, Kim HW, et al. Usefulness of assisted procedures for arteriovenous fistula maturation without compromising access patency. Hemodial Int 2017;21(3):335-342

15 Lee SJ, Jeon GS, Lee B, Lee G, Lee JJ. Endovascular management in immature arteriovenous fistula for hemodialysis. Medicine (Baltimore) 2018;97(36):e12211

16 Bittl JA, Feldman RL. Cutting balloon angioplasty for undilatable venous stenoses causing dialysis graft failure. Catheter Cardiovasc Interv 2003;58(4):524-526

17 Vesely TM. Percutaneous transluminal angioplasty for the treatment of failing hemodialysis grafts and fistulae. Semin Dial 1998;11(6):351-359

18 Bittl JA. Venous rupture during percutaneous treatment of hemodialysis fistulas and grafts. Catheter Cardiovasc Interv 2009;74(7):1097-1101

19 Rundback JH, Leonardo RF, Poplausky MR, Rozenblit G. Venous rupture complicating hemodialysis access angioplasty: percutaneous treatment and outcomes in seven patients. Am J Roentgenol 1998;171(4):1081-1084 